\title{
The effects of electroconvulsive therapy on tardive dystonia or dyskinesia induced by psychotropic medication: a retrospective study
}

This article was published in the following Dove Press journal:

Neuropsychiatric Disease and Treatment

3 July 2014

Number of times this article has been viewed

\author{
Norio Yasui-Furukori' \\ Atsuhiro Kikuchi' \\ Hiroshi Katagai ${ }^{1,2}$ \\ Sunao Kaneko' \\ 'Department of Neuropsychiatry, \\ Hirosaki University School \\ of Medicine, ${ }^{2}$ Department of \\ Neuropsychiatry, Hirosaki-Aiseikai \\ Hospital, Hirosaki, Japan
}

Correspondence: Norio Yasui-Furukori Department of Neuropsychiatry, Graduate School of Medicine,

Hirosaki University

Hirosaki 0.36-8562, Japan

Tel +8I I7 2395066

Fax +8 I I7 2395067

Email yasufuru@cc.hirosaki-u.ac.jp
Background: Tardive dystonia and dyskinesia are potentially irreversible neurological syndromes. Successful electroconvulsive treatment (ECT) has been reported by multiple sources; however, the existing retrospective reviews and open prospective trials provide little information on the response rate.

Methods: Eighteen consecutive patients with tardive dystonia or dyskinesia received a standard course of ECT to treat abnormal movement. The severity of the tardive dystonia and dyskinesia was evaluated using the Abnormal Involuntary Movement Scale (AIMS) before and after the course of ECT. The patients who displayed a greater than 50\% improvement in the AIMS score were classified as the responders.

Results: The mean AIMS score decreased from 19.1 \pm 4.7 to 9.6 \pm 4.2 . There were seven responders among the 18 patients, which yielded a $39 \%$ response rate.

Conclusion: ECT has a moderate but significant effect on tardive dystonia and dyskinesia. Keywords: tardive dystonia, tardive diskinesia, ECT, medication

\section{Introduction}

Tardive dystonia and dyskinesia are potentially irreversible neurological syndromes. They are characterized by choreiform and athetoid movements that primarily affect the buccal, facial, and lingual muscles, but may also affect the extremities and trunk. In neuroleptic-treated patients, the estimated prevalence of tardive dyskinesia is $15 \%-20 \%,{ }^{1}$ with a range of $0.5 \%-56 \%{ }^{2,3}$ In one study, the cumulative rates of tardive dyskinesia after 1, 2, and 3 years of antipsychotic treatment were $25 \%, 34 \%$, and $53 \%$, respectively. ${ }^{4}$ A greater risk of tardive dyskinesia has been associated with; a history of electroconvulsive treatment (ECT), higher mean daily and cumulative antipsychotic doses, and the presence of extrapyramidal signs early in treatment. ${ }^{4,5}$

Several case reports have described the successful application of ECT to treat tardive dystonia ${ }^{6-9}$ and dyskinesia. ${ }^{2,10-13}$ These case reports suggest that a publication bias may be overemphasizing the positive results. While a retrospective review or an open prospective trial should provide a clearer picture of the response rates by including the nonresponders, there has been little information on the response rates for ECT. Therefore, we examined the effects of ECT on tardive dystonia and dyskinesia.

\section{Methods}

This study was approved by the local ethics committee of Hirosaki University Hospital and was carried out in accordance with the latest version of the Declaration 
of Helsinki. All participants provided written informed consent prior to participation in the study.

ECTs were performed in approximately 15 patients per year in our university hospital between 2005 and 2010. The aim of ECT is to treat depression, schizophrenia symptoms, and movement disorders. Seventy-four patients were treated with ECT, including 39 patients with depression affective disorders, 15 patients with schizophrenia, two patients with neurosis, and 18 patients with tardive involuntary movement disorders. The subjects included in this study consisted of 18 consecutive patients with tardive involuntary movement disorders who underwent ECT. Table 1 provides descriptive data on the demographic and clinical characteristics of the 18 subjects. The pharmacological histories of the subjects were unknown. No psychopathological evaluations other than establishing abnormal involuntary movements were conducted because the mental conditions of all subjects were stable.

Tardive dystonia and dyskinesia were assessed using the Abnormal Involuntary Movements Scale (AIMS), ${ }^{14}$ with repeated administrations throughout the course of ECT. A response was defined as a $50 \%$ improvement relative to the baseline, and a partial response was defined as a $25 \%$ improvement relative to the baseline. The subjects included ten women and eight men between the ages of 19 and 65 years ( mean \pm standard deviation $=42 \pm 14$ ); 13 patients had been diagnosed with schizophrenia, and the remaining five patients had been diagnosed with unipolar depression. The patients were prescribed one or two antidepressants or antipsychotic medications during ECT. The medications were maintained at a constant rate during the course of ECT, with only minor dosage adjustments and no absolute changes to the antidepressant or antipsychotic agents.

All patients received bilateral ECT, which was performed three times per week, using a Thymatron ${ }^{\circledR}$ machine (Nihon Koden Medical, Tokyo, Japan). Each ECT procedure was conducted between 8.30 am and 10 am at Hirosaki University Hospital. Patients fasted for at least 12 hours before the ECT procedure. During each ECT procedure, 0.5-1 mg/kg propofol was administered intravenously to each patient, and succinylcholine $(0.5 \mathrm{mg} / \mathrm{kg})$ was administered as a muscle relaxant after the induction of anesthesia. The stimulus intensity was determined with a dose titration procedure (starting at 25.2 millicoulomb), and the seizure threshold was identified in the first session. The electrical dose was then determined by multiplying the seizure threshold dose by 2.5 in the following sessions. The seizure duration (tonic and clonic) was recorded by the isolation of one leg by inflation of a cuff to over $200 \mathrm{mmHg}$ to assess the quality of the seizure. If the duration of the seizure was less than 20 seconds, then the electrical dose was increased by $50 \%$. The patients' ventilation was supported using $100 \%$ oxygen through a bag and mask until the resumption of respiration. We continuously monitored the electrocardiogram, arterial oxygen saturation (pulse oximetry), noninvasive blood pressure, and heart rate of the patients during the procedure. The length of the ECT course ranged from six to 15 treatments administered twice per week. The average overall course length

Table I Characteristics of the 18 subjects

\begin{tabular}{|c|c|c|c|c|c|c|c|c|c|c|}
\hline \multirow{2}{*}{$\begin{array}{l}\text { Patient } \\
\text { number }\end{array}$} & \multirow{2}{*}{$\begin{array}{l}\text { Age } \\
\text { (years) }\end{array}$} & \multirow{2}{*}{ Sex } & \multirow{2}{*}{$\begin{array}{l}\text { Type of } \\
\text { tardive } \\
\text { disorder }\end{array}$} & \multirow[t]{2}{*}{ Diagnosis } & \multirow{2}{*}{$\begin{array}{l}\text { Potential causal } \\
\text { medication and their } \\
\text { daily doses }\end{array}$} & \multirow{2}{*}{$\begin{array}{l}\text { Current } \\
\text { medications } \\
\text { and their daily doses }\end{array}$} & \multirow{2}{*}{$\begin{array}{l}\text { Number } \\
\text { of sessions }\end{array}$} & \multicolumn{2}{|c|}{ AIMS scores } & \multirow[t]{2}{*}{ Outcome } \\
\hline & & & & & & & & Baseline & Final & \\
\hline I & 65 & $\mathrm{~F}$ & Dyskinesia & Depression & Milnacipran 60 mg/day & No medication & 6 & 14 & 2 & $\mathrm{R}$ \\
\hline 2 & 62 & $\mathrm{~F}$ & Dyskinesia & Depression & Haloperidol 6 mg/day & Risperidone $2 \mathrm{mg} /$ day & 12 & 22 & 10 & $\mathrm{R}$ \\
\hline 3 & 63 & $\mathrm{~F}$ & Dyskinesia & Depression & Haloperidol 12 mg/day & Olanzapine 5 mg/day & 10 & 18 & 10 & PR \\
\hline 4 & 33 & $M$ & Dyskinesia & Schizophrenia & Risperidone 6 mg/day & Olanzapine 2.5 mg/day & 10 & 23 & 2 & $\mathrm{R}$ \\
\hline 5 & 30 & $M$ & Dyskinesia & Schizophrenia & Olanzapine 20 mg/day & Aripiprazole 3 mg/day & 10 & 20 & 12 & PR \\
\hline 6 & 62 & $\mathrm{~F}$ & Dystonia & Depression & Milnacipran 100 mg/day & No medication & 10 & 24 & 13 & PR \\
\hline 7 & 54 & $M$ & Dystonia & Schizophrenia & Chlorpromazine $600 \mathrm{mg} /$ day & Olanzapine 10 mg/day & 10 & II & 3 & $\mathrm{R}$ \\
\hline 8 & 28 & $M$ & Dystonia & Schizophrenia & Risperidone $6 \mathrm{mg} /$ day & Risperidone 2 mg/day & 9 & 21 & 6 & $\mathrm{R}$ \\
\hline 9 & 30 & $M$ & Dystonia & Schizophrenia & Risperidone $4 \mathrm{mg} /$ day & Risperidone I mg/day & 10 & 22 & 13 & PR \\
\hline 10 & 32 & $M$ & Dystonia & Schizophrenia & Risperidone 8 mg/day & Risperidone $2 \mathrm{mg} /$ day & 12 & 25 & 14 & PR \\
\hline 11 & 37 & $M$ & Dystonia & Schizophrenia & Perospirone 24 mg/day & Risperidone $3 \mathrm{mg} / \mathrm{day}$ & 15 & 26 & 17 & PR \\
\hline 12 & 59 & $\mathrm{~F}$ & Dyskinesia & Schizophrenia & Perospirone $48 \mathrm{mg} /$ day & Aripiprazole 12 mg/day & 8 & 16 & 7 & $\mathrm{R}$ \\
\hline 13 & 55 & $\mathrm{~F}$ & Dyskinesia & Depression & Sulpiride $150 \mathrm{mg} /$ day & No medication & 15 & 21 & 12 & PR \\
\hline 14 & 39 & $\mathrm{~F}$ & Dystonia & Schizophrenia & Mosapramine $150 \mathrm{mg} /$ day & No medication & 10 & 13 & 10 & PR \\
\hline 15 & 33 & $\mathrm{~F}$ & Dystonia & Schizophrenia & Perospirone 12 mg/day & Aripiprazole $3 \mathrm{mg} /$ day & 15 & 21 & 10 & $\mathrm{R}$ \\
\hline 16 & 19 & $\mathrm{~F}$ & Dystonia & Schizophrenia & Risperidone 4 mg/day & Aripiprazole 3 mg/day & 10 & 12 & 7 & PR \\
\hline 17 & 28 & $M$ & Dyskinesia & Schizophrenia & Perospirone $12 \mathrm{mg} /$ day & Aripiprazole 1.5 mg/day & 8 & 12 & 9 & PR \\
\hline 18 & 32 & $\mathrm{~F}$ & Dystonia & Schizophrenia & Aripiprazole 24 mg/day & Aripiprazole 3 mg/day & 8 & 23 & 15 & PR \\
\hline
\end{tabular}

Abbreviations: AIMS, Abnormal Involuntary Movement Scale; PR, partial responders; R, responders; F, female; M, male. 
was $10.5 \pm 2.4$ treatments. If the patients had no response to ECT, they declined ECT after the sixth session.

Several factors, including the AIMS and Global Assessment of Functioning scores, were compared using paired $t$-tests. Multiple regression analyses were used to detect the correlations between the degree of improvement in the AIMS score and several factors, including; age, sex, the type of movement disorder, the diagnosis, and the baseline AIMS score. Sex, the type of movement disorder, and the diagnosis were analyzed using dummy variables (male $=0$, female $=1$, tardive dyskinesia $=0$, tardive dystonia $=1$, depression $=0$, schizophrenia $=1$ ). A $P$-value of less than 0.05 was regarded as statistically significant. All analyses were performed using PASW Statistics PC software for Windows, Version 21.0.0 (SPSS Inc., Chicago, IL, USA).

\section{Results}

Figure 1 shows the changes in the AIMS scores throughout the course of the ECT for each subject. The mean AIMS score decreased from $19.1 \pm 4.7$ to $9.6 \pm 4.2$. Out of 18 patients, seven patients were responders, and eleven patients were partial responders following the ECT. There were no nonresponders. Out of the seven responders, four patients responded within two sessions. A total of $39 \%$ of the patients were responders and showed a greater than $50 \%$ improvement in their AIMS scores. The mean AIMS score significantly decreased and showed a $40 \%$ improvement. All patients tolerated the ECT well and did not present any serious adverse effects. Four patients reported a mild headache and scalp discomfort during the first several treatments, but these side effects subsided quickly. The Global Assessment of Functioning score significantly increased from $30.6 \pm 5.2$ to 50.0土6.7 $(P<0.001)$.

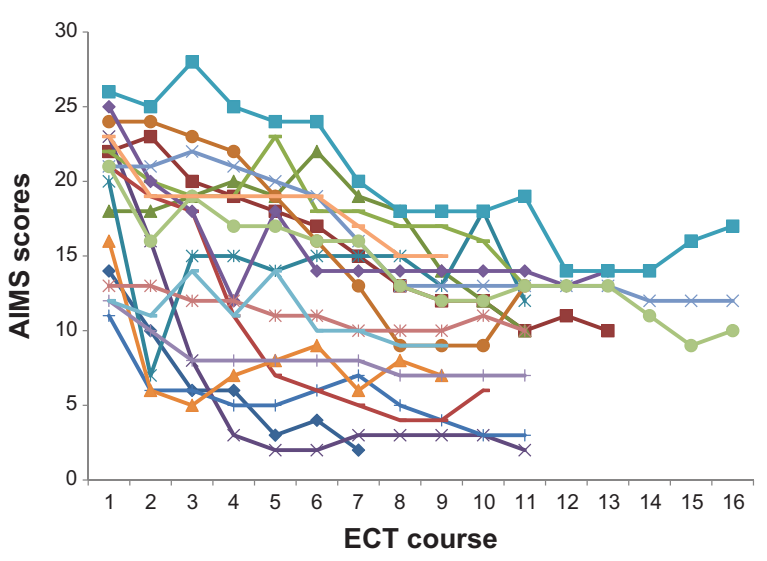

Figure I Individual AIMS score over ECT course.

Note: Significant decrease in AIMS score over number of ECT was found $(P<0.00 \mathrm{I})$. Abbreviations: AIMS, Abnormal Involuntary Movement Scale; ECT, electroconvulsive treatment.
Multiple regression analyses, including; sex, age, the type of movement disorder, the diagnosis, and the baseline AIMS score, revealed no correlations with the degree of improvement in the AIMS score.

There were no differences in the parameters of ECT delivery or the clinical information between the responders and the nonresponders.

\section{Discussion}

The results of our study indicate the effectiveness of ECT as a treatment for tardive dystonia and tardive dyskinesia. However, the efficacy of ECT for tardive dystonia and tardive dyskinesia was mild to moderate. This report is the first to provide the ECT response rate (39\%) for tardive dystonia and tardive dyskinesia. In some patients, ECT was effective within two sessions. While the response rate is not high and predicting symptom improvement is difficult, clinicians should consider ECT for patients with tardive dystonia and tardive dyskinesia. Because medication remained constant throughout the course of ECT in this study, the $39 \%$ response rate is likely accurate.

While the successful treatment of tardive dystonia and dyskinesia using ECT has been suggested in previous case reports, the single prospective study ${ }^{7}$ observed an improvement in only one patient, while eight patients remained unchanged. Many patients have undergone changes in their medication regimen. These changes may cause a withdrawal dyskinesia that spontaneously remits over time. ${ }^{15}$

ECT is thought to prevent the supersensitization of the postsynaptic dopamine receptors that contribute to the development of tardive states. ${ }^{16,17}$ These effects only occurred with concurrent neuroleptic administration, which may account for the efficacy of ECT in both hypo and hyperdopaminergic states. ${ }^{16}$ Several mechanisms of action have been proposed for ECT in tardive dyskinesia and tardive dystonia. The most commonly accepted explanation is that ECT enhances dopaminergic transmission. This enhancement may occur at the receptor or postreceptor level. ${ }^{17}$ Animal studies have demonstrated an upregulation of the GABAergic system. A change in the GABAergic system may influence abnormal movement disorders, but the evidence remains controversial. Another explanation may involve the disruption of the blood-brain barrier, which is known to occur after ECT. ${ }^{18}$ This disruption may allow increased levels of antipsychotics and antidepressants to enter the brain, potentially alleviating the motor symptoms even while the oral dose of the drug remains constant. ${ }^{19}$

There are several limitations to this case series. First, longitudinal changes in cognitive function were not evaluated after the course of ECT. ECT has been frequently 
discontinued because of the adverse cognitive effects; thus, the assessment of cognitive function and recovery during the course of ECT would be an important measure to include in a prospective study. Second, while the type and dose of medications were held constant in all patients, we were unable to control for the confounding effects of medication. Finally, this case series is limited by the retrospective design and the lack of a control group. Despite these limitations, this case series suggests that ECT may offer another potential treatment for tardive dystonia and tardive dyskinesia. Controlled studies comparing ECT to current evidenced-based strategies such as vitamin E are warranted. ${ }^{20}$ Future studies should also include comprehensive measures of cognition.

\section{Acknowledgments}

The authors would like to thank all of their coworkers on this study for their skillful contributions to collecting and managing the data.

This study was funded by a Grant-in-Aid for Scientific Research (KAKENHI) from the Japan Society for the Promotion of Research (JSPS, \# 22591271), Mitsubishi Pharma Research Foundation. Asteras Schizophrenia Research Foundation and a grant from the Hirosaki Research Institute for Neurosciences.

\section{Disclosure}

Norio Yasui-Furukori has received grant/research support or honoraria from, and been on the speakers of Astra, Dainippon, Eli Lilly, GSK, Janssen-Pharma, Meiji. Mochida, MSD, Otsuka, Pfizer, Takada and Yoshitomi. The remaining authors declare that they have no competing interests. The funders had no role in study design, data collection and analysis, decision to publish, or preparation of the manuscript.

\section{References}

1. Kennedy R, Mittal D, O'Jile J. Electroconvulsive therapy in movement disorders: an update. J Neuropsychiatry Clin Neurosci. 2003;15(4): 407-421.

2. Besson JA, Palin AN. Tardive dyskinesia, depression and ECT. Br J Psychiatry. 1991;159:446.
3. Gupta S, Mosnik D, Black DW, Berry S, Masand PS. Tardive dyskinesia: review of treatments past, present, and future. Ann Clin Psychiatry. 1999;11(4):257-266.

4. Byne W, White L, Parella M, Adams R, Harvey PD, Davis KL. Tardive dyskinesia in a chronically institutionalized population of elderly schizophrenic patients: prevalence and association with cognitive impairment. Int J Geriatr Psychiatry. 1998;13(7):473-479.

5. Woerner MG, Alvir JM, Saltz BL, Lieberman JA, Kane JM. Prospective study of tardive dyskinesia in the elderly: rates and risk factors. $\mathrm{Am} J$ Psychiatry. 1998;155(11):1521-1528.

6. Hanin B, Lerner Y, Srour N. An unusual effect of ECT on druginduced parkinsonism and tardive dystonia. Convuls Ther. 1995;11(4): 271-274.

7. Yassa R, Hoffman H, Canakis M. The effect of electroconvulsive therapy on tardive dyskinesia: a prospective study. Convuls Ther. 1990;6(3):194-198.

8. Sugawara M, Iizuka H, Kawana A, Suzuki J. Tardive dystonia and ceruletide effects: case report. Prog Neuropsychopharmacol Biol Psychiatry. 1992;16(1):127-134.

9. Postolache TT, Londono JH, Halem RG, Newmark MD. Electroconvulsive therapy in tardive dystonia. Convuls Ther. 1995;11(4):275-279.

10. Salama AA, England RD. A case study: schizophrenia and tactile hallucinations, treated with electroconvulsive therapy. Can J Psychiatry. 1990;35(1):86-87.

11. Sandyk R. The relationship between ECT responsiveness and subtypes of tardive dyskinesia in bipolar patients. Int J Neurosci. 1990; 54(3-4):315-319.

12. Ranjan R, Meltzer HY. Acute and long-term effectiveness of clozapine in treatment-resistant psychotic depression. Biol Psychiatry. 1996;40(4):253-258.

13. Nobuhara K, Matsuda S, Okugawa G, Tamagaki C, Kinoshita T. Successful electroconvulsive treatment of depression associated with a marked reduction in the symptoms of tardive dyskinesia. $J E C T$. 2004;20(4):262-263.

14. Guy W. AIMS: ECDEU Assessment Manual for Psychopharmacology. Washington, DC: Government Printing Office; 1976.

15. Hay DP, Hay L, Blackwell B, Spiro HR. ECT and tardive dyskinesia. J Geriatr Psychiatry Neurol. 1990;3(2):106-109.

16. Lerer B. Electroconvulsive shock and neurotransmitter receptors: implications for mechanism of action and adverse effects of electroconvulsive therapy. Biol Psychiatry. 1984;19(3):361-383.

17. Kapur S, Mann JJ. Role of the dopaminergic system in depression. Biol Psychiatry. 1992;32(1):1-17.

18. Bolwig TG, Hertz MM, Holm-Jensen J. Blood-brain barrier during electroshock seizures in the rat. Eur J Clin Invest. 1977;7(2):95-100.

19. Kellner CH, Beale MD, Pritchett JT, Bernstein HJ, Burns CM. Electroconvulsive therapy and Parkinson's disease: the case for further study. Psychopharmacol Bull. 1994;30(3):495-500.

20. Soares-Weiser K, Maayan N, McGrath J. Vitamin E for neurolepticinduced tardive dyskinesia. Cochrane Database Syst Rev. 2011CD000209.
Neuropsychiatric Disease and Treatment

\section{Publish your work in this journal}

Neuropsychiatric Disease and Treatment is an international, peerreviewed journal of clinical therapeutics and pharmacology focusing on concise rapid reporting of clinical or pre-clinical studies on a range of neuropsychiatric and neurological disorders. This journal is indexed on PubMed Central, the 'PsycINFO' database and CAS,

\section{Dovepress}

and is the official journal of The International Neuropsychiatric Association (INA). The manuscript management system is completely online and includes a very quick and fair peer-review system, which is all easy to use. Visit http://www.dovepress.com/testimonials.php to read real quotes from published authors. 